\title{
Reflets
}

Revue d'intervention sociale et communautaire

\section{DE GAULEJAC, Vincent (2011). Le travail, les raisons de la colère, Paris, Seuil, coll. Économie humaine, 334 p.}

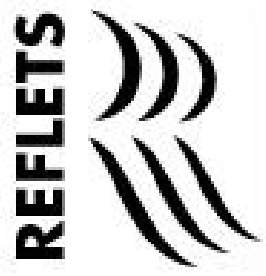

\section{Marc Charron}

Volume 17, numéro 2, automne 2011

URI : https://id.erudit.org/iderudit/1012138ar

DOI : https://doi.org/10.7202/1012138ar

Aller au sommaire du numéro

Éditeur(s)

Reflets, Revue d'intervention sociale et communautaire

ISSN

1203-4576 (imprimé)

1712-8498 (numérique)

Découvrir la revue

Citer ce compte rendu

Charron, M. (2011). Compte rendu de [DE GAULEJAC, Vincent (2011). Le travail, les raisons de la colère, Paris, Seuil, coll. Économie humaine, 334 p.] Reflets, 17(2), 218-221. https://doi.org/10.7202/1012138ar d'utilisation que vous pouvez consulter en ligne.

https://apropos.erudit.org/fr/usagers/politique-dutilisation/ 


\section{Le travail, les raisons de la colère}

DE GAULEJAC,Vincent (2011). Paris, Seuil, coll. Économie humaine, 334 p.

\section{par Marc Charron}

Professeur, Université Laurentienne

Une vague de suicides, telle une véritable épidémie, a touché les employés de certaines grandes entreprises privées françaises. Symptomatique d'un mal-être au travail, le suicide, au même titre que la dépression, le stress, l'épuisement professionnel et les congés maladie longue durée, exprime, sur le plan du vécu, la souffrance et l'impuissance des employés face aux mutations ayant cours dans le monde du travail. Les causes profondes de ce mal-être au travail, de cette colère qui gronde chez les travailleurs et qui ne trouve pas de lieux d'expression dans les mouvements collectifs de contestation sont au cœur de cette recherche menée parVincent de Gaulejac.

L'ouvrage est divisé en trois parties. La première s'attarde à nommer le problème à travers un examen critique des principaux termes employés pour désigner cette nouvelle réalité qui envahit de plus en plus le monde du travail : souffrance au travail, violence, risque psychosocial et mal-être. S'appuyant sur de nombreux documents, rapports ministériels et transcriptions de procès et témoignages, l'auteur reconstitue les liens entre la vague de suicides comme symptôme emblématique du mal-être des travailleurs, les politiques de réorganisation et le mode de gestion mis en vigueur par les directions d'entreprises. Au-delà de la sympathie momentanée exprimée par les dirigeants et les politiques lors de ces événements tragiques, ce qui frappe, c'est l'incompréhension et le refus des employeurs de prendre quelque responsabilité, voire de chercher à prendre en compte la nature du problème. 
Dans un monde du travail où la concurrence est vive et où la priorité est l'amélioration de la productivité, la flexibilité et la rentabilité de l'entreprise, les dommages collatéraux en coûts humains et sociaux importent peu, le suicide demeurant aux yeux des dirigeants une défaillance ou une faiblesse individuelle. Après tout, les êtres humains sont des ressources humaines, un capital qu'il faut rentabiliser.

La seconde partie examine le mal-être dans les institutions publiques. Elle interpellera davantage les intervenantes et intervenants sociaux œuvrant dans les agences ou organismes tels les hôpitaux, les centres de santé communautaire, le Centre d'accès aux services communautaires ou les Sociétés d'aide à l'enfance. Là aussi, la perspective du capital humain en est venue à s'imposer comme conception dominante, renforcée par un processus de révision générale des politiques publiques (RGPP). Comme le souligne l'auteur, la recette est simple :

Il convient de démontrer que l'administration [publique] est peu efficace et coûteuse afin d'introduire une nouvelle conception de la gestion qui va la rendre plus efficiente. Pour ce faire, il faut substituer la culture des résultats à la culture des moyens, la culture commerciale à la culture de service public [axée sur la mission], la culture managériale à la culture administrative. (p. 12)

L'évaluation permanente accompagne une telle transformation administrative où l'utilisateur de service n'est plus une personne, mais un coût, une somme à débourser. Lorsqu'on passe plus de temps à rédiger un rapport sur l'activité qu'à la mener,l'évaluation tourne à l'obsession. Il ne s'agit pas seulement d'inventorier le travail qui se fait, mais de prescrire simultanément un travail qui aurait dû idéalement être effectué. À ce jeu, on est toujours en défaut ou dans l'attente d'une reconnaissance qui ne vient jamais, car on aurait pu en accomplir plus. Cet écart rejaillit sur l'intervenante sociale qui doit porter le fardeau de ce manque, accuser cette incapacité à se réaliser pleinement. Cela est vécu avec d'autant plus d'intensité que la mission de l'organisation sociale qui lui servait de garde-fou et à laquelle elle avait adhéré est placée en contradiction avec une recherche intensive d'efficacité. Ainsi, la mission d'un hôpital n'est plus de soigner des patients, mais 
d'avoir un budget équilibré. Les objectifs financiers mènent le bal au nom de la lutte au déficit, comme dans le dernier budget du gouvernement fédéral. Le ministre des Finances décrète une réduction de $10 \%$ dans tous les ministères, et le reste de l'appareil s'évertue à la réaliser, même au risque de quelques dommages collatéraux : pertes d'emplois, stress invivable, déprime généralisée et surcharge de travail.

La troisième partie aborde les sources structurelles de ce malêtre. Sous la pression du rendement actionnariale ou d'une lutte au déficit à tout craindre, les organisations se transforment en véritables systèmes paradoxants : univers complexe mêlant idéal et réel, traversé par des exigences multiples, souvent opposées et irréconciliables. Or, comme l'avait montré Bateson, le paradoxe induit un processus de subordination-domination qui conduit l'individu à l'impuissance, à être toujours en défaut. Le paradoxe de l'urgence fait qu'on court après le temps, et qu'on manque cruellement de temps pour accomplir correctement ce qu'on doit accomplir. Alors on s'invente des stratégies pour gagner du temps, tout en sachant bien que plus on en gagne, moins on en a. Le paradoxe de l'excellence durable est du même ordre. Si l'injonction à l'excellence c'est chercher à se dépasser, alors cela nous entraîne dans une course sans fin où, incapables d'en donner toujours plus sur la longue durée, on fait face à son impuissance, celle d'avoir atteint ses limites. Nous sommes alors seuls confrontés à nos déficits de performance. Le paradoxe de l'autonomie se situe au point de jonction entre un individu dont on exalte l'autonomie, mais qui est pris dans un faisceau de contraintes qui la limitent d'autant. Devant cette profusion de paradoxes, il y a deux types de réactions possibles à l'égard des organisations : les réactions défensives (adhésion sans faille aux jeux des injonctions paradoxales gestionnaires au prix de l'instauration d'une coupure avec son moi, ses valeurs, ses engagements; en somme l'individu compris dans sa subjectivité) et les réactions de dégagement (sortir du système paradoxal en s'échappant, en rompant les liens qui nous lient au travail-congé de maladie, cessation d'emploi — ou en le transformant le système de l'intérieur). La transformation interne renvoie à la création de collectifs qui développent, au moyen 
d'une métacommunication, une réflexion commune centrée sur l'analyse des effets paradoxants des organisations actuelles et sur la promotion d'un discours alternatif porteur de sens nouveau.

D'ailleurs, Le travail, les raisons de la colère se veut une contribution à cette métacommunication souhaitée pour sortir du piège des systèmes organisationnels paradoxants, en dénonçant les leurres d'organisations qui disent à la fois satisfaire les désirs de reconnaissance, de perfection et de toute-puissance et procurer les moyens d'entreprendre, de s'investir à fond la caisse dans des projets, de réaliser des œuvres.

S'inscrivant dans une perspective de sociologie clinique, cet ouvrage deVincent de Gaulejac illustre bien que les organisations sont de véritables structures sociomentales où s'enchevêtrent ce qui vient de l'organisation se fixant comme idéal et ce qui vient des individus aux prises avec cette quête, "cet impossible rêve ", comme disait Jacques Brel. 